\title{
Assessment of the Impact of Corpus luteum on in Vitro Maturation and Developmental Competence of Dromedary Camel Oocytes
}

\author{
M.A.M. Aggag*, A.Y.A. Hashaad**, A.R.M. El-Khawagah*, M.M.M. Kandiel*, \\ KarimaGh. M. Mahmoud*** \\ *Department ofTheriogenology, Faculty of Veterinary Medicine, Benha University, \\ **Qalioub Veterinary Department, the Directorate of Veterinary Medicine, Qalyoubia, and \\ ***Department of Animal Reproduction and A.I., National Research Centre, Cairo, Egypt.
}

\begin{abstract}
$\mathbf{T}$
O ASCERTAIN the effect of corpus luteum (CL) on the oocytes retrieval, quality and in vitro developmental competence in camels, ovaries were collected from apparent healthy slaughtered she-camel during breeding season and categorized according to the presence (group I) or absence (Group II) of CL. Oocytes were aspirated from 2-5 mm antral follicles on the surface of pathological-free-ovaries, quantified and morphologically graded depending upon the cumulus investment and cytoplasmic distribution. Oocytes from each group were matured in vitro and examined for nuclear maturation in fixed slides after 30 hours of incubation. In vitro matured oocytes from each group were fertilized with epididymal sperm suspension and assessed for the cleavage and development to morula and blastocyst stages at $3^{\text {rd, }} 5^{\text {th }}$ and $7^{\text {th }}$ day, respectively. Under the present experimental conditions, the accessible data showed a significant influence of $\mathrm{CL}$ presence on thequantity, quality and in vitro nuclear maturation of retrieved oocytes in camels. The number of all retrieved oocytes classes was higher in the absence of CL. While the rate of excellent and poor quality oocytes retrieval was higher $(p<0.05)$ in the absence of $\mathrm{CL}$, the good quality oocytes were retrieved at higher rate $(p<0.001)$ in the presence of CL. The highest rate of metaphase II (MII) was recorded in oocytes harvested from ovaries had no CL. Nevertheless, CL had no marked influence on the rate of cleavage, morula and blastocyst formation. It could be concluded that the presence of CL is not a barrier against embryo developmental competence, though its marked influence on ovarian follicular activity.
\end{abstract}

Keywords: Camel, Corpus luteum, Embryo developmental competence, In-vitro oocytes maturation, In-vitro fertilization.

\section{Introduction}

Camels are seasonal breeders, induced ovulator animals [1], displaying their maximum reproductive efficiency during the period from December to April in Egypt [2]. The reproductive efficiency of camels under natural conditions is generally low, due to the relatively short breeding season, long pre-pubertal period, long gestation period, long calving interval, and the lack of use of assisted reproductive techniques such as embryo transfer and artificial insemination [3]. In Egypt, there are few attempts to establish in vitro fertilization (IVF) techniques in dromedary camel [4-6].
For in vitro oocyte maturation, it has been reported that the rate and the quality of oocyte yield from slaughtered animals' ovaries were affected by several factors including the ovarian morphology [7], methods of oocyte retrieval [8], season [9] and ovarian status [10].

Former studies reported many inconsistencies about the influence of corpus luteum (CL) on the oocytes developmental competence. In camel, it was noticed that the presence of CL during early pregnancy did not inhibit the growth and development of ovarian follicles [11]. In bovines, it has been reported that the oocytes recovered from ovaries having CL showed high maturation 
rate, and the absence of this structures was associated with poor in vitro oocytes development [12]. On the other hand, Shabankareh et al.[13] clearly proved that CL exerts negative effects on the developmental competence of bovine oocytes in vitro. So, the present study was designed to verify the impact of corpus luteum on the oocytes retrieval, quality and in vitro developmental competence in camels.

\section{Material and Methods}

All Chemicals were purchased from SigmaAldrich Co., except tissue culture medium (TCM199) and fetal calf serum (FCS) were purchased from Gibico BRL (Grand Island, New York, USA), and ringer lactate solution (ADWIA Pharmaceuticals Co.) was bought from the pharmacy.

\section{Ovaries collection, grouping and oocyte} harvesting

Ovaries were collected from apparent healthy slaughtered she-camel of unknown reproductive history at El-Warrak slaughter house, Cairo, within 2 hours (h) of slaughter according to Lee and Fukui [14]. Ovaries, free from pathological lesions or abnormalities, were transported to the laboratory in $0.9 \% \mathrm{NaCl}$ supplemented with gentamicin $(10 \mu \mathrm{g} / \mathrm{mL})$ and maintained at 30 $38^{\circ} \mathrm{C}$ in thermos-container. Collected ovaries were washed three times by warm saline and were categorized according to the presence (group I) or absence (Group II) of corpus luteum.

Oocytes were aspirated from 2-5 mm antral follicles on the surface of ovaries with syringe fitted with $18 \mathrm{G}$ needle according to Ali and AbdelRazek [15]. The harvested oocytes were washed 2-3 times in maturation medium, examined morphologically with stereo-microscope and graded depending upon the cumulus investment and cytoplasmic distribution into excellent (A), good (B), fair (C) and poor (D) according to Kharche et al. [16].

\section{In vitro maturation and nuclear maturation evaluation}

Oocytes maturation was carried out according to Mahmoud et al. [4]. Briefly, oocytes $(n=10$ $15 / 100 \mu \mathrm{l}$ of maturation medium) were cultured in 4-well plastic Petri-dishes (pre-incubated for a minimum of $2 \mathrm{~h}$ before culturing of oocytes), covered with mineral oil layer (to prevent evaporation and contamination with microorganisms) and incubated for $30 \mathrm{~h}$. At the end of the culture period, slides were prepared for the evaluation of nuclear maturation according to the procedure described by Tarkowski[17]. Briefly, cumulus cells were mechanically removed by gentle pipetting, oocytes were transferred to $1 \%$ hypotonic sodium citrate solution for 10 min., placed on a microscope slide with a minimal amount of hypotonic solution and fixed with methanol/glacial acetic acid (3:1) before being stained with $1 \%$ orcein stain. The state of nuclear maturation,Teleophase-I (TI) and/or MII stages,was determined as described earlier by Mahmoud [18]. TI was defined as completion of separation of two chromosome sets and MII was haploid set of chromosomes after emission of first polar body.

\section{In vitro fertilization and embryo culture}

Freshly harvested epididymal spermatozoa for IVF were prepared as described by Moawad et al. [19]. Camel epididymis, collected from a local abattoir (Toukh, Qalyoubia), was washed with sterile saline, isolated, incised longitudinally, rinsed 3-4 times with $2 \mathrm{ml}$ of bovine serum albumin (BSA) free BOmedium [20] containing $10 \mathrm{mg} / \mathrm{ml}$ heparin and $2.5 \mathrm{mM}$ caffeine, and centrifuged at $800 \times \mathrm{g}$ for $10 \mathrm{~min}$. Sperm pellets were re-diluted with $\mathrm{BO}$ medium containing 20 $\mathrm{mg} / \mathrm{ml} \mathrm{BSA}$ to adjust spermatozoa concentration to $2.5 \times 10^{6} \mathrm{sperm} / \mathrm{ml}$.

Matured oocytes were washed three times in BO medium containing $10 \mathrm{mg} / \mathrm{ml} \mathrm{BSA}$ and were co-cultured ( $\mathrm{n}=5-10$ oocytes/droplet) with $100 \mu \mathrm{l}$ droplets of sperm suspension under mineral oil for $5 \mathrm{~h}$. After that the oocytes were washed in TCM199 to remove attached spermatozoa and cumulus cellsby vortex. Presumptive fertilized oocytes were transferred to TCM-199 culture droplets and incubated for 7-8 days with renewal of the culture media every other day. The cleavage was assessed after $72 \mathrm{~h}$ of culture (Day $0=$ day of insemination). The number of embryos developed to morula and blastocyst stages was assessed on the $5^{\text {th }}$ and $7^{\text {th }}$ day, respectively. The morphological appearance of embryos was evaluated under an inverted microscope. The cleavage and blastocyst rates were calculated from the total number of inseminated oocytes.

\section{Statistical analysis}

Data were presented as mean $( \pm$ S.E. $)$ and 
analyzed for significance by Student t-testand Chi-square test using SPSS (ver.16) statistical software. Differences were considered to be significant at $\mathrm{P}<0.05$.

\section{Results and Discussion}

Effect of reproductive status on oocyte retrieval

The mean number of retrieved oocytes per ovary per conducted trial $(n=13)$ significantly $(\mathrm{p}<0.01)$ differed between $\mathrm{CL}$ and non-CL groups (2.98 \pm 0.31 vs. $5.84 \pm 0.59$, respectively). Also, the overall oocyte retrieval rate per ovary markedly $(p<0.0001)$ varied between evaluated groups (244/84 ovaries (2.91) and 648/114 (5.68), respectively) (Table 1 ).

The number of all retrieved oocytes classes was higher in the absence of CL (group II). The excellent and poor quality oocytes retrieval rate was higher $(\mathrm{p}<0.05)$ in the second group (CL absent), while the good quality oocytes were retrieved in higher rate $(\mathrm{p}<0.001)$ in the first group (CL present) (Fig. 1). Oocytes were classified into excellent, good, fair and poor quality depending upon the cumulus investment and cytoplasmic distribution. The rate of retrieved oocyte in each class was analyzed by Chi-square test.

TABLE 1. Effect of corpus luteum presence on oocyte retrieval rate from camel ovaries during the breeding season.

\begin{tabular}{lccc}
\hline \multicolumn{1}{c}{ Parameter } & Group I & Group II & P value \\
\cline { 2 - 3 } & (CL present) & (CL absent) & \\
\hline Number of ovaries & 84 & 114 \\
Total number of retrieved oocytes & 244 & 648 & \\
Number of retrieved oocytes per ovary (Mean \pm SEM) & $2.98 \pm 0.31$ & $5.84 \pm 0.59 * *$ & $>0.01$ \\
Overall retrieval rate (\%) & 2.91 & $5.68 * * * *$ & $>0.0001$ \\
\hline
\end{tabular}

Differences in retrieval rate among groups were analyzed with Chi-Square analysis. Means of groups were analyzed with Student t-test.

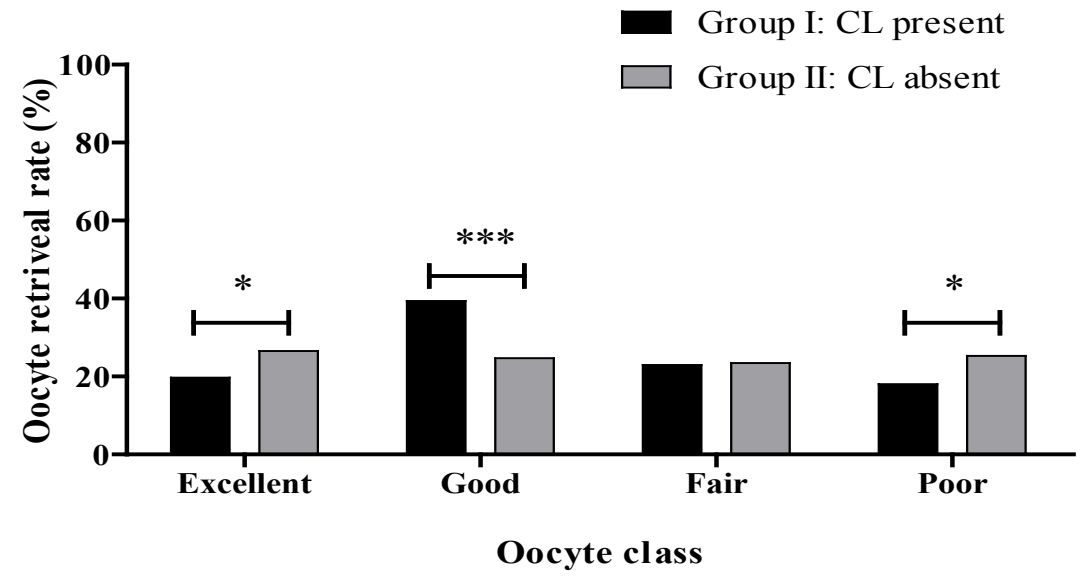

Fig. 1. Effect of corpus luteum presence of the quality of retrieved camel oocytes during the breeding season.

A clear relation has been found between the follicular growth and CL development [21]. It has been reported that the number of oocytes per ovary in camel is affected by ovarian status, animal ages, site of the ovary, breeding season and/or their interactions [22]. Corpora lutea affect ovarian follicular dynamics in both ovaries by a systemic effectwith an evidence for a local ipsilateraleffect [23]. The present findings came in agreement with those reported by Abdoon [24], but disagree with studies by Torner et al. [25], Khalil [26] and Farag et al. [11], who declared that the presence of CL during early pregnancy did not inhibit the growth and development of camel ovarian follicles and 
that the average number of oocytes per ovary were nearly similar in pregnant and non-pregnant camels.

Animal reproductive status has been found to influence the frequency distributions of oocytes at different stages of maturation [26]. In thisrespect, the data obtained in the current study is coordinated with Abdoon [24] and Amer et al. [27] who mentioned that the presence of CL significantly reduces the number of ovarian follicles as well as the quality of the oocytes. Khalil [26] established that a lower rate of type $\mathrm{A}$ and higher rate of type $\mathrm{B}$ and $\mathrm{C}$ is associated with increasing level of follicular atresia, which is tremendously high during gestation period. The reasonsfor the superiority of the ovaries without CL over those CL-bearing ovaries is not clear. There were many former trials to explain the mechanism of CL interference with oocyte population and quality. Some authors denoted that the CL may alter follicles growth rate resulting in atresia [28], while others related this to the conceptus effects, asa local suppressor on follicular development in the ipsilateral ovary, to prevent luteolysis as mechanism of maternal recognition of pregnancy [29].

Effect of reproductive status on the nuclear maturation of retrieved oocyte

The effect of CL on rate of nuclear maturation in camel oocytes in vitro is presented in Table 2.A significant difference $(\mathrm{p}<0.05)$ has been found between matured oocytes from ovaries with CL and without CL in terms of GV and MII stages. The highest rate of GV stage has been recorded in those retrieved from ovaries containing CL. While, the highest value of MII stage has been observed in the matured oocytes retrieved from ovaries without CL.

TABLE 2. Effect of corpus luteum presence on in-vitro nuclear maturation in camels.

\begin{tabular}{|c|c|c|c|c|c|c|c|c|}
\hline \multirow{3}{*}{ Parameter } & \multirow{2}{*}{\multicolumn{3}{|c|}{$\begin{array}{c}\text { Group I } \\
\text { (CL present) }\end{array}$}} & \multirow{2}{*}{\multicolumn{3}{|c|}{$\begin{array}{c}\text { Group II } \\
\text { (CL absent) }\end{array}$}} & \multicolumn{2}{|c|}{ P value } \\
\hline & & & & & & & \multirow{2}{*}{$\begin{array}{c}\text { Chi- } \\
\text { square }\end{array}$} & \multirow{2}{*}{$\begin{array}{c}\text { Student } \\
t \text {-test }\end{array}$} \\
\hline & $\mathbf{N}$ & $\%$ & Mean \pm SE & $\mathbf{n}$ & $\%$ & Mean \pm SE & & \\
\hline GV & 26 & 36.62 & $36.35 \pm 1.53^{*}$ & 29 & 30.53 & $29.89 \pm 0.85$ & 0.41 & $>0.05$ \\
\hline GVBD & 10 & 14.08 & $13.83 \pm 0.67$ & 13 & 13.68 & $14.02 \pm 0.55$ & 0.95 & 0.83 \\
\hline MI & 6 & 8.45 & $8.19 \pm 0.99$ & 7 & 7.37 & $6.70 \pm 1.62$ & 0.79 & 0.48 \\
\hline AI & 2 & 2.82 & $2.57 \pm 1.39$ & 3 & 3.16 & $2.47 \pm 1.23$ & 0.89 & 0.95 \\
\hline TI & 8 & 11.27 & $11.25 \pm 0.90$ & 8 & 8.42 & $8.55 \pm 1.28$ & 0.54 & 0.16 \\
\hline MII & 19 & 26.76 & $23.61 \pm 2.84$ & 35 & 36.84 & $37.83 \pm 2.76^{*}$ & 0.17 & $>0.05$ \\
\hline $\begin{array}{l}\text { Maturation } \\
(\mathrm{TI}+\mathrm{MII})\end{array}$ & 27 & 38.03 & $39.04 \pm 2.49$ & 42 & 44.21 & $45.06 \pm 2.69$ & 0.42 & 0.18 \\
\hline
\end{tabular}

Data were presented as mean $\pm \mathrm{SE}$ ( $\mathrm{n}=6$ replicates) and were analyzed with Student $\mathrm{t}$-test. Nuclear maturation rates were analyzed with Chi-square test. GV, GVBD, MI, AI, TI and MII referred to Germinal vesicle, Germinal vesicle breakdown, Anaphase-I, Telophase-I and Metaphase II stages, respectively.

To undergo a successful fertilization and embryonic development, a complete cytoplasmic and nuclear maturation is necessary [30]. The degree of cumulus cell expansion, meiotic division and evenly granulated dark ooplasm are significant in evaluating in vitro maturation [31]. In vivo and in vitro nuclear maturation behave the same pattern [32]. Oocyte meiotic maturation is a complex process at which germinal vesicle breakdown (GVBD) takes place, chromosomes condense, metaphase plate forms, meiosis I fulfilled, the first polar body formed and is arrest at Metaphase-II [23]. The data currently presented verified a clear impact of $\mathrm{Cl}$ presence on camel oocyte maturation in vitro. Khalil [26] has been reported that the CL presence tended to lower the number of oocytes at $\mathrm{GV}$ and increased the rate of oocytes at GVBD and M II stages. The difference in camel oocytes attained nuclear maturation might be interrelated with the variation in time needed for the maturation in vitro [25].As the oocytes of pregnant camels require $36 \mathrm{~h}$ of maturation to reach levels of $>50 \%$ metaphase II stage, whereas $32 \mathrm{~h}$ is sufficient for the oocytes from non-pregnant animals [25]. Mahmoud et al. [4] 
that the oocyte maturation time in vitro was $30 \mathrm{~h}$ in camels, regardless the presence or absence of CL.Khatir et al.[34] found high rate (63\%) of the oocytes reached to metaphase II-stage after 36 $\mathrm{h}$ of culture in vitro. Noteworthy, all retrieved camel oocytes (CL-bearing and non-CL bearing) were examined for maturational changes after 3640 hours of culture.

Effect of reproductive status on the embryonaldevelopmental competence

The data presented in Fig. 2 revealed that the
CL was none significantly influenced on the rate of cleavage, morula and blastocyst formation. The developed camel embryos from oocytes matured in vitro $(\mathrm{n}=66)$ retrieved from $\mathrm{CL}$ bearing ovaries were $36(54.55 \%), 18(27.27 \%)$ and $4(6.06 \%)$ reached to cleavage, morula and blastocyst stages, respectively. In the interim, oocytes retrieved from non-CL bearing ovaries $(\mathrm{n}=72)$ and in vitro fertilized were $38(55.56 \%)$, $18(25.00 \%)$ and $5(6.94 \%)$ reached to cleavage, morula and blastocyst stages, respectively. These results concomitant with those reported formerly by Scholkamy et al. [6] in camel.

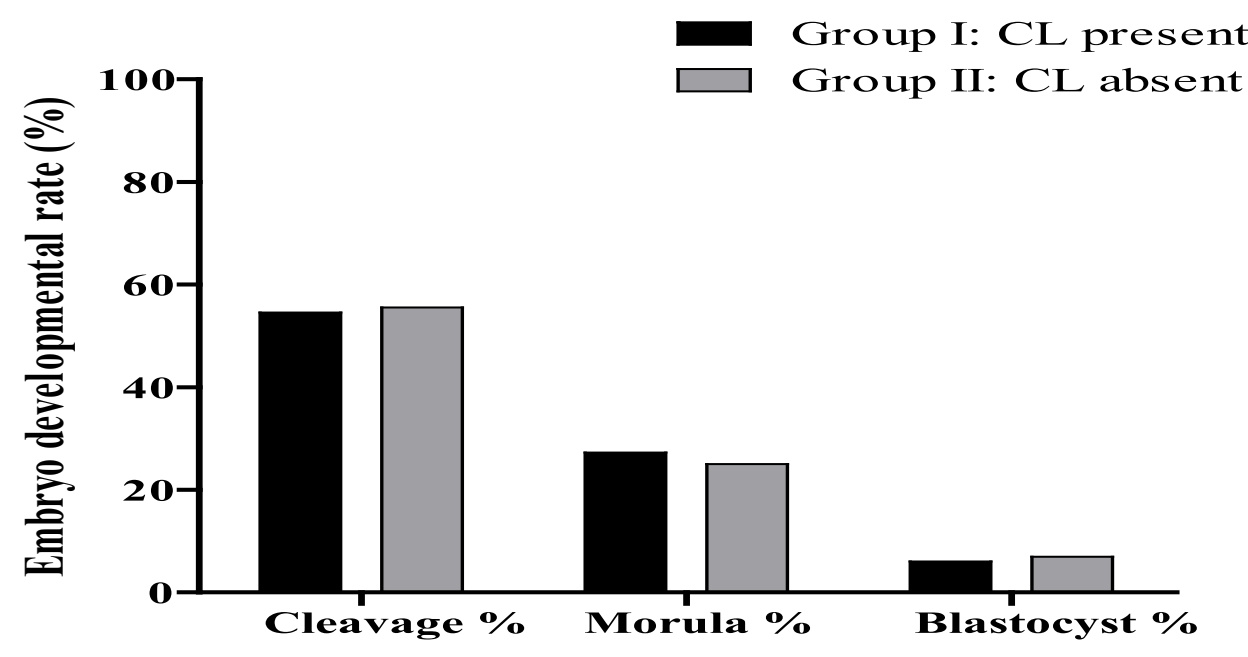

Fig. 2. Effect of corpus luteum on in-vitro embryo developmental competence in camels.

\section{Conclusions}

It could be concluded that the presence of CL, associated with pregnancy, negatively impacts on follicular growth and oocyte maturation. Nevertheless, these oocytes sustain its appropriateness for fertilization and embryo development likewise those retrieved from ovaries has no CL.

\section{References}

1. Bravo, P.W., Stabenfeldt, G.H., Lasley, B.L. and Fowler, M.E. (1991) The effect of ovarian follicular size on pituitary and ovarian responses to copulation in domesticated South American camelids. Biol. Reprod., 45, 553-559.
2. Basiouni, G.F. (2007) Follicular wave pattern, folliculogenesis and assisted reproductive techniques in the non-pregnant female dromedary camel (Camelusdromedarius). J. Biol. Sci.,7, 10381045 .

3. Skidmore, J.A. (2005) Reproduction in dromedary camels: an update. Anim.Reprod., 2, 161-171.

4. Mahmoud, K.Gh.M., El-Shahat, K.H. and El-Nattat, W.S. (2003) Chromosome configuration during in vitro maturation of dromedary camel oocytes. Vet. Med. J. (Giza) 51, 411-420.

5. El-Harairy M.A., Shamia S.H.M., Abdel-Khalek A.E. and Khalil W.A. (2007) Effect of pregnancy status and harvesting technique on recovery rate and categories of dromedary camel oocyte. Egyptian $J$. Vet. Basic Applied Physiol., 2, 255-268. 
6. Scholkamy, T.H., El-Badry, D.A. and Mahmoud, K.Gh.M. (2016) Developmental competence of dromedary camel oocytes fertilized in vitro by frozen-thawed ejaculated and epididymal spermatozoa. Iranian J. Vet. Res., 17, 253-258.

7. Gandolfi, F., Luciano, A.M., Modina, S., Ponzini, A., Pocar, P., Armstrong, D.T. and Lauria, A. (1997)The in vitro developmental competence of bovine oocytes can be related to the morphology of the ovary. Theriogenology, 48, 1153-1160.

8. Hamano, S. and Kuwayama M. (1993) In vitro fertilization and development of bovine oocytes recovered from the ovaries of individual donors: a comparison between the cutting and aspiration method. Theriogenology, 39, 703-712.

9. Sghiri, A. and Driancourt, M.A. (1999) Seasonal effect of fertility and ovarian follicular growth and maturation in camels (Camelus dromedarius). Anim. Reprod. Sci., 55, 223-37.

10. Boediono, A., Rajamahendran, R., Saha, S., Sumantri, C. and Suzuki, T. (1995) Effect of the presence of a CL in the ovary on oocyte number, cleavage rate and blastocyst production in vitro in cattle. Theriogenology, 43, 169 (abstract).

11. Farag, I.M., Girgis, S.M., Zowail, M.E., AbdAllah, S.M., El-Nahas, E.M. and Abd ElHafez, M.A.M. (2012) Factors affecting in vitro maturation, yield and quality of camel (Camelusdromedarius) oocytes. Theriogenology Insight, 2, 209-231.

12. Varisanga, M.D., Sumantri, C., Murakami, M., Fahnidin, M. andSuzuku, T. (1998) Morphological classification of the ovaries in relation to the subsequent oocyte quality for IVF-induced bovine embryos. Theriogenology, 50, 1015-23.

13.Shabankareh, H.K., Shahsavari, M.H., Hajarian, H., Moghaddam, G. (2015) In vitro developmental competence of bovine oocytes: Effect of corpus luteum and follicle size. Iran J. Reprod. Med., 13, 615-622.

14. Lee, E.S. and Fukui, Y. (1995) Effect of various growth factors in a defined culture medium on in vitro development of bovine embryos matured and fertilized in vitro. Theriogenology, 44, 71-83.
15.Ali, A. and Abdel-Razek, A.K.H. (2001) Comparison of number and quality of oocytes in the Egyptian buffaloes (Bubalus bubalis), cows (Bos taurus) and camels (Camelus dromedarius). Assiut Vet. Med. J., 45, 317-325.

16.Kharche, S.D., Goel, A.K., Jindal, S.K., Sinha, N.K. andYadav, P. (2008) Effect of somatic cells co-culture on cleavage and development of in vitro fertilized embryos. Indian J. Anim.Sci.,78, 686692.

17.Tarkowski, A.K. (1966) An air-drying method for chromosome preparation from mouse eggs. Cytogenetics, 5, 394-400.

18.Mahmoud, K.Gh.M. (2004) Meiotic stages and incidence of diploid oocytes in Egyptian cattle and buffalo. Assiut Vet. Med. J., 50, 336-47.

19.Moawad, A.R., Darwish, G.M., Badr, M.R. and El-Wishy, A.B. (2011) In vitro fertilization of Dromedary camel (Camelus dromedaries) oocytes with epididymal spermatozoa. Reprod. Fertil.Dev., 24, 192-193.

20.Brackett, B.G. and Oliphant, G. (1975) Capacitation of rabbit spermatozoa in vitro. Biol. Reprod., 12, 260-274.

21-Rexroad, Jr.C.E.and Casida, L.E. (1977) Effect of injection of progesterone into one ovary of PMSGtreated anestrous ewes on follicle growth and ovarian estradiol-17 beta. J. Anim.Sci., 44, 84-88.

22.Abdel-KhalekE., A., El-Harairy, M.A., Shamiah, Sh.M. and Khalil, W.A. (2010) Effect of ovary preservation period on recovery rate and categories of dromedary camel oocytes. Saudi J. Biol. Sci., 17, 231-235.

23.Contreras-Solis, I., Diaz, T., Lopez, G., Caigua, A., Lopez-Sebastian, A. andGonzalez-Bulnes A. (2008) Systemic and intra-ovarian effects of corpus luteum on follicular dynamics during estrous cycle in hair breed sheep. Anim. Reprod. Sci., 104, 47-55.

24.Abdoon, A.S.S. (2001) Factors affecting follicular population, oocyte yield and quality in camels (Camelusdromedarius) ovary with special reference to maturation time in vitro. Anim.Reprod. Sci., 66, 71-79. 
25.Torner, H., Heleil, B., Alm, H., Ghoneim, I.M., Srsen, V., Kantiz, W.,Tuchscherer, A. andFattouh, E.M. (2003) Changes in cumulus-oocyte complexes of pregnant and non-pregnant camels (Camelus dromedarius) during maturation in vitro. Theriogenology, 60, 977-987.

26. Khalil, W.A. (2005) Differences between farm animals in (IVM and IVF) in vitro maturation and in vitro fertilization. Master Thesis, Animal Production, Faculty of Agriculture, Mansoura University.

27.Amer, H.A., Hegab, A.O. and Zaabal, S.M. (2008) Effects of ovarian morphology on oocyte quantity and quality, granulosa cells, in vitro maturation and steroid hormone production in buffalo. Anim. Reprod., 5, 55-62.

28.Rexroad, C.E. and Casida, L.E. (1975) Ovarian follicular development in cows, sows and ewes in different stages of pregnancy as affected by number of corpora lutea in the same ovary. J. Anim.Sci., 41, 1090-1097.

29.Driancourt, M.A., Thatcher, W.W., Terqui, M. and Andrieu, D. (1991) Dynamics of ovarian follicular development in cattle during estrous cycle, early pregnancy and in response to PMSG. Domest. Anim. Endocrinol., 8, 209-221.
30. Roberts, R., Franks, S. and Hardy, K. (2002) Culture environment modulates maturation and metabolism of human oocytes. Hum. Reprod., 17, 2950- 2956.

31.Cetica, P.D., Dalvit, G.C. and Beconi, M.T. (1999) Effect of recovery method on yield of bovine oocytes per ovary and their developmental competence after maturation, fertilization and culture in vitro. Theriogenology, 41, 1061-1068.

32. Hyttel, P., Callesen, H. and Greve T. (1986) Ultrastructural features of preovulatory oocyte maturation in superovulated cattle. J. Reprod. Fertil., 76, 645- 656.

33. Modina, S., Luciano, A.M., Vassena, R., BaraldiScesi, L., Lauria, A. and Gandolfi, F. (2001) Oocyte developmental competence after in vitro maturation depends on the persistence of cumulusoocyte communications which are linked to the intracellular concentration of cAMP. Ital. J. Anat. Embryol., 106, 241-248.

34. Khatir, H., Anouassi, A. and Tibary, A. (2004) Production of dromedary (Camelusdromedarius) embryos by IVM and IVF and co-culture with oviductal or granulosacells. Theriogenology, 62, $1174-1185$.
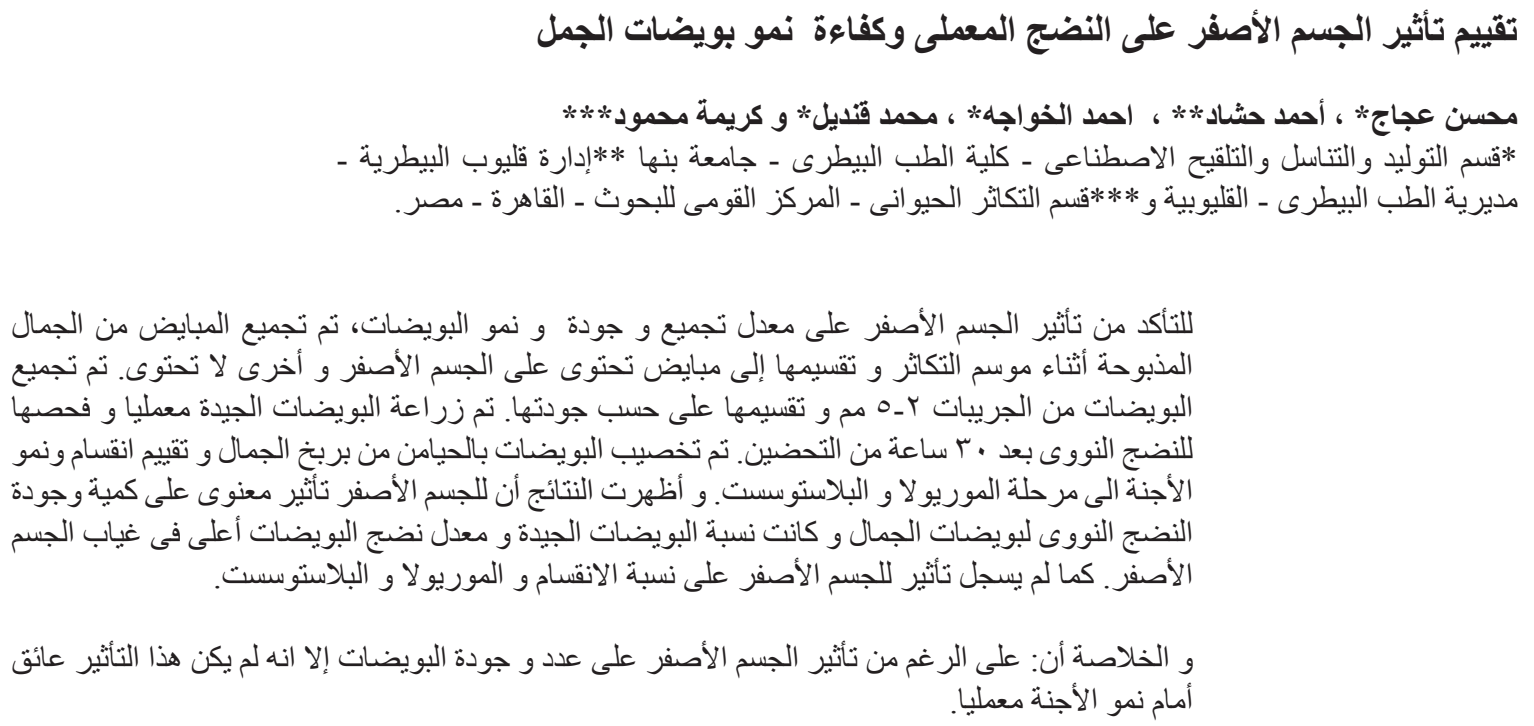